\title{
El control de convencionalidad en la responsabilidad del Estado colombiano
}

\author{
Conventionality control in the responsibility of the Colombian State
}

\author{
William Eugene Ulrich Astaiza (iD \\ Universidad Cooperativa de Colombia
}

\begin{abstract}
RESUMEN El presente artículo busca clarificar y explicar la institución jurídica del control de convencionalidad que aplica para Colombia, con fundamento en el artículo 93 de la Constitución de 1991, y cómo el progreso de la normativa interamericana ha calado hondo en la jurisprudencia tanto del Consejo de Estado como dentro de la Corte Constitucional, que en sus fallos la han venido aplicando en procura de una nueva concepción de Estado convencionalmente cumplido y responsable de acuerdo con los lineamientos de la CIDH y la Corte IDH. El trabajo parte de la pregunta: ¿cómo se aplica el control de convencionalidad dentro de la responsabilidad del Estado colombiano? Para lo cual se acudirá a autores en el tema, además de un uso de la jurisprudencia tanto de la Corte IDH como del Consejo de Estado y la Corte Constitucional de Colombia. El objetivo es analizar la aplicación y uso del control de convencionalidad en la responsabilidad del Estado colombiano.
\end{abstract}

PALABRAS CLAVE Control de convencionalidad, responsabilidad extracontractual, Estado colombiano.

ABSTRACT This article seeks to clarify and explain the legal institution of conventionality control that applies to Colombia based on article 93 of the 1991 Constitution, and how the progress of inter-American regulations has penetrated deeply into the jurisprudence of both the Council of State, as within the Constitutional Court, who in their rulings have been applying this in search of a new conception of the State Conventionally fulfilled and responsible in accordance with the guidelines of the IHR Commission and the IHR Court. This work starts from the question: How is conventionality control applied within the responsibility of the Colombian State? For which authors on the subject will be used, in addition to a copious use of the jurisprudence of both the InterAmerican Court and the Council of State and the Constitutional Court of Colombia. As an objective, we analyze the application and use of the control of conventionality in the responsibility of the Colombian State. 
KEYWORDS Conventionality control, extracontractual liability, Colombian State.

\section{Introducción}

El control de convencionalidad como exigencia para los países que conforman el Pacto de San José o la Convención Americana de Derechos Humanos (CADH) nace a partir de la necesidad de reforzar con obligatoriedad inmediata la aplicación del mencionado tratado, que a la luz del principio pacta sunt servanda obliga a un Estado a cumplir con lo pactado, y evita que puedan alegarse inconvenientes de tipo legal interno como obstáculo en la aplicación, como lo ha dispuesto el artículo 27 de la Convención de Viena sobre el derecho de los tratados.

La obligación de un Estado parte de la CADH de ajustar su ordenamiento y sus actuaciones a lo dispuesto en el mencionado tratado responde a la dinámica de internacionalización de los derechos humanos y la constante necesidad de su aplicación sin resultar éstos mermados, ya sea por actuaciones o interpretaciones que pongan en entredicho su efectividad. La órbita de convencionalidad, si así se le quiere denominar, busca sin interrupciones ajustar a cada Estado parte a las regulaciones que mediante tratados se ha obligado a cumplir.

El Estado colombiano ha sido especialmente cauteloso con este tema, ya que ha sido obligado a responder por sus faltas a nivel interamericano en numerosas ocasiones, ${ }^{1}$ y por ello el Consejo de Estado ha sido abanderado en el cumplimiento de las obligaciones de convencionalidad de tipo difuso que le asisten.

Es así que el presente trabajo busca no solo presentar un panorama de significación del control de convencionalidad en su más amplia acepción, sino presentar la manera en que se ha responsabilizado al Estado colombiano por sus actuaciones en las sentencias del máximo ente de lo contencioso administrativo, atendiendo a lo dispuesto en la CADH y en la jurisprudencia de la Corte IDH, que, como se explicó, ha tratado en no una, sino en varias ocasiones a los lineamientos de responsabilidad internacional y los ha aplicado a su jurisprudencia evitando la declaración internacional de responsabilidad del Estado, es decir, como instancia interna de control.

1. Ejemplos claros y no exhaustivos de la responsabilidad interamericana de Colombia son los casos de la masacre de la Rochela con Colombia, Masacre de Pueblo Bello con Colombia y Masacre de Mapiripán con Colombia. 


\section{El control de convencionalidad en la jurisprudencia de la Corte Interamericana de Derechos Humanos: Génesis, tratamiento y casos particulares en Colombia}

El control de convencionalidad como institución jurídica de corte interamericano ha sido tratada, quizás no con gran profundidad, desde la sentencia Myrna Mack Chang con Guatemala, en la que, en voto concurrente razonado, el juez Sergio García Ramírez afirmó que no es posible seccionar al Estado en su responsabilidad, es decir, no es posible afirmar que un solo ente sea el responsable y que sólo este debe responder. Por el contrario, debe ser el Estado en su integralidad el que se ve abocado a la responsabilidad: «El Estado viene a cuentas en forma integral, como un todo. En este orden, la responsabilidad es global, atañe al Estado en su conjunto y no puede quedar sujeta a la división de atribuciones que señale el derecho interno». Si bien es un primer momento de inclusión del término, éste quedó sin un tratamiento de fondo adecuado, ya que pareciera ser simplemente obiter dicta del voto razonado que hace alusión al régimen de responsabilidad que le asiste a los Estados signatarios de la $\mathrm{CADH}$, sin llegar a una explicación de fondo sobre la verdadera importancia y significado de la expresión.

En el caso Almonacid Arellano con Chile, de 2005, se propone una nueva dimensión de entendimiento de la expresión control de convencionalidad que muestra su verdadero significado y alcance, que deja claro que los jueces en su rol deben aplicar las leyes que los rigen, y que dejar de hacerlo significaría una investigación no solo disciplinaria, sino penal. ${ }^{2}$ Pero, a la luz de la $\mathrm{CADH}$, se adquieren obligaciones mucho más grandes y de calado interamericano. Es así que el control de convencionalidad de corte difuso recae sobre los jueces, que deberán sopesar el efecto de las normas que aplican y si están o no a tono con las obligaciones del Estado en materia de derechos humanos. De no pasar el «filtro» de convencionalidad, deberá, de manera argumentada, inaplicarse y preferirse la Convención y la interpretación que ha hecho la Corte IDH acerca del caso, ya que no puede una norma interna mermar los efectos útiles del instrumento internacional.

En Colombia existe, de acuerdo con el artículo 4 de la Constitución, la «excepción de inconstitucionalidad», ${ }^{3}$ que permite a los operadores jurídicos sustraerse de

2. En Colombia se hace alusión al artículo 413 del Código Penal, que establece: «El servidor público que profiera resolución, dictamen o concepto manifiestamente contrario a la ley, incurrirá en prisión de 48 a 144 meses, multa de 66,66 a 300 salarios mínimos legales mensuales vigentes, e inhabilitación para el ejercicio de derechos y funciones públicas de 80 a 144 meses».

3. Reza el mencionado artículo: «La Constitución es norma de normas. En todo caso de incompatibilidad entre la Constitución y la ley u otra norma jurídica, se aplicarán las disposiciones constitucionales. Es deber de los nacionales y de los extranjeros en Colombia acatar la Constitución y las leyes, y respetar y obedecer a las autoridades». 
aplicar una norma que no aprueba el análisis de ponderación constitucional o convencional debido. Así, el juez deberá - de manera razonada- sustentar el motivo de preferencia de la carta o la Convención sobre la norma en conflicto, lo que pone un instrumento válido para control a manos de los jueces en Colombia (Gil Botero, 2019: 84), de tal suerte que, atendiendo lo anterior, se cumple con el control difuso de convencionalidad.

En otras palabras, existe una línea argumentativa que explicita que los jueces, en todos sus niveles y disciplinas, están en la obligación de aplicar la $\mathrm{CADH}$, aun por encima de la Constitución misma (Gil Botero, 2019: 193), en categoría de control de convencionalidad. Pero no solo será dejar de aplicar normas con dicho fundamento: se requiere que el ordenamiento interno de una nación esté en consonancia o armonía con la normatividad interamericana. Así, juega un rol determinante el principio de interpretación conforme, ${ }^{4}$ que ha sido definido por Ferrer Mac-Gregor (2011: 549) como:

La técnica hermenéutica por medio de la cual los derechos y libertades constitucionales son armonizados con los valores, principios y normas contenidos en los tratados internacionales sobre derechos humanos signados por los Estados, así como por la jurisprudencia de los tribunales internacionales (y en ocasiones otras resoluciones y fuentes internacionales), para lograr su mayor eficacia y protección.

Eduardo Ferrer Mac-Gregor, en voto razonado al fallo Cabrera García y Montiel Flores con México, propone un análisis muy pormenorizado de qué es y qué implica el control de convencionalidad, argumentando que la utilización de dicho mecanismo no desconoce ni busca que el ordenamiento jurídico del Estado sea sustituido por el ámbito interamericano, sino que solo propone la búsqueda de un sistema que irrigue a cada país signatario, lográndose así que los derechos, garantías y principios de la $\mathrm{CADH}$ sean una realidad y no una mera carta de buenas intenciones sin ningún tipo de refuerzo.

Continúa el mencionado voto estableciendo que todos los jueces, en atención a su facultad de control difuso de convencionalidad, son en realidad jueces intera-

4. En Colombia este principio ha sido plasmado en la Constitución Política en su artículo 93, que establece: «Los tratados y convenios internacionales ratificados por el Congreso, que reconocen los derechos humanos y que prohíben su limitación en los estados de excepción, prevalecen en el orden interno. Los derechos y deberes consagrados en esta Carta, se interpretarán de conformidad con los tratados internacionales sobre derechos humanos ratificados por Colombia. El Estado colombiano puede reconocer la jurisdicción de la Corte Penal Internacional en los términos previstos en el Estatuto de Roma adoptado el 17 de julio de 1998 por la Conferencia de Plenipotenciarios de las Naciones Unidas y, consecuentemente, ratificar este tratado de conformidad con el procedimiento establecido en esta Constitución. La admisión de un tratamiento diferente en materias sustanciales por parte del Estatuto de Roma con respecto a las garantías contenidas en la Constitución tendrá efectos exclusivamente dentro del ámbito de la materia regulada en él». 
mericanos, por lo que su tarea será, claramente, la de mantener el funcionamiento y efecto útil de la Convención; 5 y agrega que deberá atender de igual forma la interpretación que hace de ella la Corte IDH, del cual es el intérprete autorizado. Así, el valor del precedente de la Corte es total y no podrá ignorarse, según lo dispone el Pacto de San José: «Los Estados partes en la Convención se comprometen a cumplir la decisión de la Corte en todo caso en que sean partes». ${ }^{6}$ Es decir, dicho fallo resultará obligatorio para todos los poderes públicos de un Estado. Claro está que dicho decisum se extiende a las partes del fallo y para ellos será obligatorio el cumplimiento de la providencia, ya que los efectos son de naturaleza inter partes. Esto hace surgir la pregunta: ¿deben los demás Estados acatar los fallos de la Corte IDH aun cuando éstos no sean los sujetos bajo juicio? O, más aún, ¿podrá pregonarse que existen efectos erga omnes de los fallos de la Corte? Esta es la cuestión que a continuación se atenderá.

La extensión de la ratio decidendi de los fallos de la Corte IDH ha sido tenida en cuenta como criterio de convencionalidad en la jurisprudencia de Colombia, ${ }^{7}$ en el que teniéndose en cuenta el precedente de López con Venezuela, ${ }^{8}$ se estableció que los funcionarios de elección popular no pueden ser sancionados con la pérdida de su investidura a través de mecanismos diferentes a una sanción penal, cuestión que se acompasa convencionalmente con lo establecido en la $\mathrm{CADH}$ y se ajusta a lo que ha interpretado el órgano establecido para ello, que es la Corte IDH; lo cual no prueba per se que sea del todo vinculante para los Estados la jurisprudencia que ha obligado a otros. Pero, como acota Hitters (2008: 148): «Lo cierto es que ninguna norma del Pacto de San José le da el carácter vinculante, válido para todos los asuntos a los decisorios de la Corte IDH, salvo obviamente, para el caso concreto».

A pesar de la inexistencia de una norma expresa acerca de la obligatoriedad de la obediencia del precedente interamericano - salvo que la sentencia involucre a un Estado, en cuyo caso estará obligado a obedecer-, está de por medio el principio de buena fe que predica la Convención de Viena, que establece que la interpretación de los tratados deberá hacerse de buena fe y atendiendo a los fines para los cuales se pactó el tratado en primer lugar. Entonces bien, al ser éste un tratado de derechos humanos, no está de más predicar una obligatoriedad, aunque sea de tipo moral y encadenada a la buena fe frente al precedente interamericano.

\footnotetext{
5. Caso Gelman con Uruguay, Corte Interamericana de Derechos Humanos, 2011.

6. Caso La Cantuta con Perú, Corte Interamericana de Derechos Humanos, 2006.

7. Sentencia 1.131-2014, Consejo de Estado de Colombia, 2017.

8. Caso López con Venezuela, Corte Interamericana de Derechos Humanos, 2011.
} 


\section{El control de convencionalidad en la jurisprudencia del Consejo de Estado de Colombia}

La jurisprudencia del Consejo de Estado de Colombia ha sido especialmente prolija en cuanto a la aplicación y cuidado del control de convencionalidad, aunque en su momento hubo posturas al interior de la corporación que favorecían los postulados de la Constitución Política, dejando de lado los de la CADH.

Tal es el caso de la destitución e inhabilidad de la senadora Piedad Córdoba. Se observa que la sala plena de lo contencioso administrativo acogió el punto de vista positivo frente a la capacidad del procurador de destituir e inhabilitar a funcionarios de elección popular, ${ }^{9}$ cuestión altamente debatida al interior de la corporación, que consideró a posteriori, en un cambió de su postura, que el artículo 23.2 de la $\mathrm{CADH}$ establecía con claridad que la sanción de destitución e inhabilidad de un funcionario electo debía darse mediante sentencia ejecutoriada de un juez penal, cuestión que escapa a las competencias de un funcionario administrativo como el procurador. $^{10}$

El Consejo de Estado ha tratado temas coyunturales que por su naturaleza atentatoria de los derechos humanos han requerido de un análisis más extenso que de costumbre frente a la responsabilidad extracontractual del Estado. A partir de lo establecido por el artículo 90 de la Constitución, que creó el régimen de responsabilidad del Estado colombiano, ${ }^{11}$ debe atenderse más allá de la reparación de naturaleza patrimonial a un análisis profundo de la significación del término víctima, que es precisamente el querer de la $\mathrm{CADH}$ en su artículo $63.1{ }^{12}$ en el que queda claro que no solo deberá atenderse a un análisis económico del problema. Pues si bien dicho ítem es importante, también lo serán otras medidas que de acuerdo con la naturaleza del daño sufrido proveerán una reparación efectiva y llevarán a la persona afectada a una situación statu quo ante o lo más cercano al estado en que se encontraba antes de ser afectado. ${ }^{13}$

9. Sentencia 1210-11, Consejo de Estado de Colombia, 2016.

10. Sentencia 1.131, Consejo de Estado de Colombia, 2014.

11. Establece dicho artículo: «El Estado responderá patrimonialmente por los daños antijurídicos que le sean imputables, causados por la acción o la omisión de las autoridades públicas. En el evento de ser condenado el Estado a la reparación patrimonial de uno de tales daños, que haya sido consecuencia de la conducta dolosa o gravemente culposa de un agente suyo, aquél deberá repetir contra éste».

12. La CADH, en su artículo 63, reza: «Cuando decida que hubo violación de un derecho o libertad protegidos en esta Convención, la Corte dispondrá que se garantice al lesionado en el goce de su derecho o libertad conculcados. Dispondrá, asimismo, si ello fuera procedente, que se reparen las consecuencias de la medida o situación que ha configurado la vulneración de esos derechos y el pago de una justa indemnización a la parte lesionada».

13. Resolución 60/147 de Naciones Unidas, 2005. 
Entre los casos más conocidos del Consejo de Estado en que se haya aplicado un primer momento del control de convencionalidad, está el conocido como «Los decapitados del Valle», ${ }^{14}$ en el que un escuadrón de la muerte de la Policía mató, decapitó y mutiló los cuerpos de cuatro personas. Este hecho llevó a cuestionar las obligaciones internacionales del Estado colombiano frente a graves violaciones de los derechos humanos, lo que dejó en claro que dentro del sistema interamericano de derechos humanos el Estado ha aceptado compromisos frente a su defensa y protección, situación que de ser desconocida podría llevar a la responsabilidad internacional. Véase cómo, a la luz de los compromisos adquiridos, el Consejo de Estado se refirió a dichas obligaciones:

En otros términos, cuando se habla del análisis de hechos relacionados con la violación de derechos humanos, según los parámetros normativos y descriptivos contenidos en los preceptos de la Carta Política y en las normas internacionales que regulan la materia, el juez de lo contencioso administrativo no debe estar limitado por su función principal, es decir, la de establecer y decretar el resarcimiento económico de un perjuicio cuya valoración económica y técnica es posible en términos actuariales, sino que debe ir mucho más allá, con el fin de que el principio de reparación integral se vea claramente materializado, para lo cual debe aplicar el conjunto de normas que le brindan suficientes instrumentos dirigidos a que se pueda materializar un efectivo restablecimiento integral del daño.

Además de las reparaciones pecuniarias por daños materiales e inmateriales, se ordena a la Policía Nacional que, en pública ceremonia donde estén presentes los familiares de los difuntos, se pidan las correspondientes excusas; se promocionen a través de medios de naturaleza pedagógica los derechos humanos en la institución; se entregue, de ser posible, material didáctico; y se ordena que en la estación de Policía de la ciudad de Tuluá, lugar de los hechos, se publique en lugar visible la sentencia para que sea leída por quien lo quiera por un periodo de seis meses.

Aunque incipiente, se observa un esfuerzo del Consejo de Estado de cumplir con las normativas internacionales a las que el Estado colombiano se ha obligado. Constituye un verdadero control difuso el que se hace en la mencionada sentencia, ya que no solo se aplica el criterio de reparación de los perjuicios materiales e inmateriales (económico), sino que se va más allá y se aplican medidas de reparación como las excusas públicas y la formación de una cátedra (medidas de satisfacción) que lleve a sensibilizar a los miembros de la fuerza pública para que lo vivido no vuelva a ocurrir (garantía de no repetición).

De acuerdo con Henao (2015: 85), la reparación in natura con o sin equivalente pecuniario es una realidad que dentro de la reparación directa contra el Estado debe

14. Sentencia 19.996, Consejo de Estado de Colombia, 2008. 
observarse, ya que si bien no en todos los casos una reparación provendrá de una vulneración de derechos humanos (Brewer-Carías y Santofimio Gamboa, 2013: 247), el verdadero sentido de la reparación es compensar a la víctima por un hecho dañoso o, como lo denomina la normativa constitucional colombiana, «antijurídico», en el que existirá la obligación, según lo establecido en la Convención en su artículo 63, de reparar las consecuencias de la acción del Estado. En el mismo sentido se pronunció la Corte IDH en el caso Velázquez Rodríguez con Honduras, al establecer que

El Estado está en el deber jurídico de prevenir, razonablemente, las violaciones de los derechos humanos, de investigar seriamente con los medios a su alcance las violaciones que se hayan cometido dentro del ámbito de su jurisdicción a fin de identificar a los responsables, de imponerles las sanciones pertinentes y de asegurar a la víctima una adecuada reparación..$^{15}$

Visto lo anterior, y de acuerdo con el principio de subsidiariedad, es el Estado el primer llamado a garantizar las disposiciones de la CADH y de organizar su normatividad interna de acuerdo con éste, para que las reparaciones que se hagan prima facie en sede nacional sean justas y no se requiera de la atención a dichos asuntos por parte de la Corte IDH que, claro está, solo podrá atender casos que hayan pasado por instancias nacionales, como lo pregona el artículo 46 de la Convención (Ledesma, 2007: 24-41). Es así que, si la reparación atiende a criterios de justicia y cumple con la integralidad (Calderón Gamboa, 2013: 155) que le asiste a un caso en que se han violado derechos consagrados en la Convención, no podrá la Corte actuar como una «cuarta instancia», ya que no es de su competencia revisar fallos de instancias nacionales; solo podrá actuar cuando de aquéllos se pueda deprecar que se han violado las normas de la CADH y que haya inactividad o ineficiencia por parte del Estado en cuanto al acceso a la justicia. ${ }^{16}$

Asimismo, el Consejo de Estado ha establecido que es menester de la jurisdicción interna reparar los perjuicios que se ocasionan desconociendo las disposiciones convencionales, constitucionales y legales, en el caso de homicidio a una persona protegida, acto especialmente execrable a la luz de las obligaciones de un Estado. Deberá atenderse entonces a la reparación in natura, en que no solo se ordenan las reparaciones del caso, sino que se ordenan las medidas propias de una violación a los derechos humanos, cuestión consistente en garantías de no repetición, medidas de satisfacción (solicitud de perdón en un medio de amplia circulación) y divulgación extensa del fallo. ${ }^{17}$

15. Caso Velázquez Rodríguez con Honduras, Corte Interamericana de Derechos Humanos, 1988, página 36, párrafo 174 .

16. Informe 2/05, Comité Interamericano de Derechos Humanos, 2005.

17. Sentencia 49.878, Consejo de Estado de Colombia, 2019. 
El Consejo de Estado propuso recientemente una cuestión problemática en cuanto a temas convencionales. Esto ocurrió respecto de la Convención de Ottawa y su aplicación en Colombia, ya que el sentido jurisprudencial que había adoptado el Consejo era el de talante proteccionista, según el cual se consideraba que la responsabilidad del Estado colombiano aparecía por su inactividad frente al flagelo de las minas antipersonales. ${ }^{18}$ Es así que los compromisos aceptados por el Estado en la Convención de Ottawa, contenidos en la Ley 759 de 2002, incluyen obligaciones de hacer y de no hacer. De hacer, en cuanto a que «el Estado colombiano se compromete a destruir o asegurar la destrucción de todas las minas antipersonales dentro de los plazos previstos en los artículos 4 y 5 de dicha Convención». Y de no hacer, tendientes a no emplear, almacenar o trasladar dichas armas, lo que deja tan solo existencia para fines de enseñanza, como dispone la mencionada ley.

Se entiende, desde el punto de vista convencional, la razón por la cual la responsabilidad del Estado es palpable en el caso de detonaciones de artefactos como minas antipersonal, ya que el compromiso es el de erradicar del territorio nacional dichas armas, cuestión superada por las fuerzas institucionales, quienes han destruido sus existencias. La dificultad más clara se presenta con grupos armados al margen de la ley, ya que éstos no operan observando las disposiciones de derechos humanos ni de derecho internacional humanitario, y su actuar es errático o irregular. Esta es la verdadera discusión que ha llevado a un cambio de postura radical y potencialmente problemático a manos del Consejo de Estado.

La sentencia 34.359, de 2018, presenta un panorama que pone dificultades al efecto útil de la Convención de Ottawa, ya que limita la responsabilidad del Estado a determinados hechos, en los cuales podría ser tenido como responsable por lesiones ocasionadas con minas antipersonales. ${ }^{19}$ Esto evidentemente suscitó enconada resistencia dentro de la Corporación, que se dejó consignada en sendos salvamentos de voto, en que los consejeros disidentes alegan la inconvencionalidad del fallo emitido, exponiendo de igual manera que esto responsabilizará internacionalmente al Estado colombiano:

La suscripción, ratificación e incorporación de la Convención de Ottawa implica para el Estado de Colombia adecuarse a una política de defensa de los derechos humanos de todos los ciudadanos, lograr la humanización del conflicto armado interno, proteger el ambiente sano y lograr mantener la paz, lo que permita concretar expresos, inmediatos e irrevocables mandatos de protección del derecho interna-

18. Sentencia 51.561, Consejo de Estado de Colombia, 2016.

19. Establece la mencionada sentencia: «Habrá lugar a declarar la responsabilidad del Estado por los daños causados con MAP/MUSE/AEI en casos en los que la proximidad evidente a un órgano representativo del Estado permita afirmar que el artefacto explosivo iba dirigido contra agentes de esa entidad, o suceda en una base militar con artefactos instalados por el mismo Ejército Nacional». 
cional humanitario, demandándose de dicho Estado la adopción de herramientas, acciones y medidas preventivas respecto de las minas antipersonales, que no puede suspenderse en su ejecución. ${ }^{20}$

El Consejo de Estado, en aplicación del principio stare decisis, ha sostenido esta línea argumentativa, ${ }^{21}$ que debe afirmarse es peligrosa para la responsabilidad internacional del Estado, ya que las obligaciones frente al desminado del territorio nacional son perennes, no puede argumentarse que el desconocimiento de la ubicación exacta de las minas antipersonales sea una causal para no actuar. La ingente necesidad de excluir a la población civil de los efectos nocivos de la guerra es un mandato internacional que se ha aceptado de forma plena. No puede, como equivocadamente sostiene la línea de la corporación, aducirse que la solicitud de extensión en el tiempo que hizo el Estado colombiano para erradicar las minas de diez años - que termina en el 2021- sea un argumento para excusarse de indemnizar a quienes han sido víctimas de este flagelo. ${ }^{22}$

\section{El daño a bienes constitucional y convencionalmente protegidos}

La tipología de perjuicio inmaterial conocida como la afectación a bienes o derechos constitucional o convencionalmente lesionados es el resultado de novedades jurisprudenciales del Consejo de Estado de Colombia como jueces de convencionalidad. La protección de estos bienes o derechos se presenta como una verdadera necesidad frente a las graves infracciones de derechos humanos o del derecho internacional humanitario, ${ }^{23}$ que son habituales en países en conflicto armado como Colombia. Es así que, como velo de protección, la máxima instancia de lo contencioso administrativo ha desplegado una forma de reparar que se basa en lo establecido en la Resolución 60/147 de 2005, en la que se privilegian medidas no pecuniarias como la restitución, rehabilitación y satisfacción, entre otras.

La necesidad de implementación de un sistema que propugne por la restitutio in integrum obedece a realidades que son palpables. La primera es que no siempre el equivalente pecuniario será la medida única de reparación ni la más importante. En

20. Salvamento de voto de la sentencia 34.359, Consejo de Estado de Colombia, 2018.

21. Sentencia 2017-03422, Consejo de Estado de Colombia, 2018.

22. El Estado colombiano solicitó a los Estados partes de la Convención una extensión de diez años (hasta el 1 marzo del 2021) y presentó un plan inicial de acción de tres años para avanzar en el cumplimiento de las obligaciones en materia de desminado humanitario contenidas en el artículo 5 de la Convención. «Solicitud de prórroga de la fecha limite par el cumplimiento de la destrucción de minas antipersonal en conformidad con el artículo 5 de la Convención», Convención sobre la prohibición del empleo, almacenamiento, producción y transferencia de minas antipersonales y sobre su destrucción, 10 de noviembre de 2010, disponible en https://bit.ly/3iSAIkS.

23. Sentencia 26.251, Consejo de Estado de Colombia, 2014. 
segundo lugar, para hacer un verdadero restablecimiento de la víctima a su estado previo, será menester otorgar medidas que, sin ser de naturaleza económica, ofrezcan justicia y restitución de sus derechos vulnerados, de ahí que sea tan concurrente y necesaria la «verdad, justicia y reparación» (Ley 446, de 1998) que busca la ley colombiana (Ley 1.448, de 2011).

Este perjuicio requiere, como apenas es obvio, de una vulneración a derechos contenidos en el texto constitucional o en aquellos instrumentos de que versa el artículo 93 de la Constitución, esto es, tratados de derechos humanos, que hacen parte integral del ordenamiento interno, en lo que se conoce como bloque de constitucionalidad, estableciéndose como una nueva categoría de daño inmaterial junto con las conocidas ya por la jurisprudencia del Consejo de Estado (daño a la salud, perjuicio moral).

La naturaleza de la vulneración a bienes constitucional y convencionalmente protegidos deberá ser «dañosa, negativa y antijurídica», ${ }^{24}$ lo cual pone una cuota de cumplimiento por parte de quien quiera probar que ha sido víctima de tales violaciones. El efecto dañoso será la actuación que vulnera efectivamente el derecho y que deberá ser indemnizado; la actuación desplegada actuará eliminando el derecho o imposibilitando su normal desarrollo; el efecto negativo será la imposibilidad de ejercer con libertad un derecho que constitucional o convencionalmente se encuentra amparado, o su efectiva destrucción (por ejemplo, libertad, vida, dignidad, etcétera). Cualquier actuación que viole un derecho convencional o constitucionalmente protegido será negativo, y desde luego será antijurídica aquella actuación que una persona no está obligada a soportar, sin que sea la licitud o ilicitud un factor relevante. ${ }^{25}$

Es importante destacar que la temporalidad en cuanto a estas violaciones es relativa, ya que no interesa si son temporales o permanentes. El objetivo de este tipo de reparación será el de restablecer, dentro de lo posible, a la persona a su condición previa al perjuicio, lograr el pleno disfrute de sus derechos vulnerados y evitar que vuelva a ocurrir algo igual. En cuanto a temas de naturaleza económica, será menester priorizar la reparación de tipo no pecuniaria o, que es lo mismo, mecanismos como las disculpas públicas, conmemoraciones, cátedras, medidas de no repetición, sanciones penales o disciplinarias a los responsables, etcétera.

La jurisprudencia del Consejo de Estado ha sido reiterativa en la reparación de perjuicios a personas que han sufrido violaciones a derechos humanos, $y$ ha distinguido dos cuestiones: los perjuicios materiales (lucro cesante y daño emergente) necesariamente deberán tener un iter de naturaleza económica que restablezca el daño efectivo y material que sufrió la víctima, ya que éstos pueden tasarse; en cuanto a reparaciones de perjuicios de naturaleza inmaterial, el daño moral debe, en determinados casos, someterse a presunciones, o dicho de otra manera, en los casos en que

24. Sentencia 32.988, Consejo de Estado de Colombia, 2014.

25. Sentencia LAT-229, Corte Constitucional de Colombia, 2003. 
la pérdida sea la de un ser querido, se experimenta un dolor real, ${ }^{26} \mathrm{y}$ si dicho dolor proviene de una grave infracción a los derechos humanos o al derecho internacional humanitario, los topes por indemnización podrán exceder los que habitualmente se otorgan. ${ }^{27}$ En los demás casos, la prueba de que se ha experimentado dolor o congoja serán objeto de juicio (Brewer-Carías y Santofimio Gamboa, 2013: 263).

La jurisprudencia del Consejo de Estado ha sido, frente a la reparación a los bienes constitucional o convencionalmente protegidos, uniforme, ya que ha elegido alejarse del tema económico ${ }^{28} \mathrm{y}$ acercarse a mecanismos simbólicos o de satisfacción. En aquellos casos en que ha sido necesario reparar a los afectados mediante este mecanismo, se ha acudido al uso de formas distintas a la asignación de dinero, que dicho sea de paso no es una verdadera reparación, ya que cuando se trata de derechos, supondrá tan solo una compensación y no una medida de tipo punitivo (Brewer-Carías y Santofimio Gamboa, 2013: 256-257).

En los casos en que sí acudió a los mecanismos no económicos de reparación, se observa que la utilización de éstos es muy común, dándoles un lugar especial en la parte resolutiva de la sentencia junto con los demás perjuicios que se hallaren probados dentro del proceso que se adelantó. ${ }^{29}$ Es dable establecer que la transición de un derecho apartado de los tratados internacionales es una materia en su gran mayoría superada, ya que no solo la constitucionalización del derecho en Colombia es una realidad, sino que su convencionalización está, por lo menos en las altas cortes, desarrollada a un muy alto nivel, cuestión que garantiza un verdadero tratamiento interno de las violaciones a los derechos humanos y al derecho internacional humanitario, lo que evita que lleguen los casos a instancias internacionales.

\section{La privación injusta de la libertad y la detención preventiva}

La privación injusta de la libertad y la detención preventiva han presentado una dificultad que no ha sido en su totalidad superada. Esto se debe a las dificultades es-

26. Sentencia 18.586, Consejo de Estado de Colombia, 2008.

27. Sentencia 32.988, Consejo de Estado de Colombia, 2014.

28. Existe una excepción dentro de la jurisprudencia sondeada: el caso 51.211, Consejo de Estado de Colombia, 24 de mayo de 2018, en el que se tasó de forma económica la vulneración a los bienes constitucional y convencionalmente protegidos de la siguiente manera: «Condenar a la nación, Fiscalía General de la Nación y al Ministerio de Defensa, Policía Nacional, a reconocer y pagar cada una el 50\% a título de indemnización por violación a bienes constitucional y convencionalmente protegidos, la suma equivalente a cincuenta salarios mínimos legales mensuales vigentes a favor de Michel Steven Jaimes Méndez».

29. Véase, como ejemplos de reparación sin subrogado pecuniario, las sentencias del Consejo de Estado de Colombia: 42.529, 26 de abril de 2018; 47.854, 5 de julio de 2018; 55.243, 14 de marzo de 2018; 41.548, 14 de marzo de 2018; 46.105, 10 de mayo de 2018; 51.211, 24 de mayo de 2018. 
tructurales del Estado colombiano en temas de política carcelaria y de aplicación en el ámbito judicial, ya que ha pasado la prisión preventiva de ser una medida excepcional a ser una especie de regla general, ${ }^{30}$ lo que pone en entredicho la presunción de inocencia, derecho establecido en el pináculo de cualquier sociedad respetuosa de los derechos convencionales y constitucionales.

El Grupo de Prisiones de la Universidad de los Andes elaboró un análisis detallado en cuanto a derechos humanos en el sistema penitenciario de Colombia. Este informe deja claro que el manejo que se venía haciendo frente a la prisión preventiva es inadecuado. Presenta alarmantes cifras, como que la población global en las cárceles de Colombia (hombres y mujeres) es de 80.237, de los cuales la población sindicada -es decir, aquélla que está aún pendiente por definir su situación- es de 35.227 personas. En otras palabras, cerca del $43 \%$ de la población carcelaria de Colombia está ahí de manera preventiva, lo que naturalmente resulta ser un exabrupto de considerables proporciones. ${ }^{31}$

En un esfuerzo para paliar este grave síntoma de inconvencionalidad, el Congreso de Colombia expidió la Ley 1.760 de 2015, que pretende organizar un desordenado sistema penal proporcionando un límite máximo a la prisión preventiva que pueda tener una persona. Establece la mencionada pieza normativa que dicha medida no podrá durar más de un año, cuestión que podrá prorrogarse a solicitud de la Fiscalía. Propone así un marco convencional juicioso pero quizás insuficiente para el tema de la responsabilidad estatal, ya que las demandas contra la nación siguen siendo un tema de fuerte tratamiento por parte del Consejo de Estado, aunado al hecho de que la Ley 1.786 de 2016 hace claras excepciones frente a lo anterior cuando están de por medio "procesos relacionados con justicia especializada, cuando sean tres o más los acusados; delitos de corrupción, y delitos contra la libertad, integridad y formación sexual del niño», lo que deja en entredicho los resultados de la anterior norma que fue aplaudida por la CIDH..$^{32}$

La responsabilidad del Estado en lo concerniente a la privación injusta de la libertad $^{33}$ está estrechamente ligada a la detención preventiva. ${ }^{34}$ Por motivo de la violación

30. Sentencia T-5.256.449, Corte Constitucional de Colombia, 2016.

31. Grupo de Prisiones, «Informe de derechos humanos del sistema penitenciario de Colombia (20172019)», Universidad de Los Andes, 2019, p. 15, disponible en https://bit.ly/3iOGQeb.

32. «Informe sobre medidas dirigidas a reducir el uso de la prisión preventiva en las Américas», Comisión Interamericana de Derechos Humanos, OEA/Ser.L/V/II.163, 3 de julio de 2017, p. 63, disponible en https://bit.ly/3gPdiem.

33. Caso Yarce y otras con Colombia, Corte Interamericana de Derechos Humanos, 2016.

34. Frente a la responsabilidad del Estado colombiano por privación injusta de la libertad, la Corte Constitucional ha unificado su postura dejando en claro que no todo caso de detención que resulte en la libertad del procesado será sin dudar una causal de responsabilidad del Estado. Deberá caso por caso analizar el Consejo de Estado o el juez administrativo los hechos y las pruebas para así determinar si 
a este fundamental derecho, se ha visto condenado el Estado colombiano a pagar multimillonarias sanciones, ya que lo ha hecho sin contar con los elementos materiales probatorios o de forma caprichosa, situación que ha llevado a reparar a aquella persona que ha sufrido del presidio no solo por medio de una indemnización, sino también por mecanismos simbólicos, cumpliendo con los lineamientos de la Corte IDH. ${ }^{35}$

El análisis de convencionalidad que es necesario para este tema debe por obligación ser riguroso, ya que está de por medio lo establecido en el artículo 7 de la $\mathrm{CADH}$, que prescribe el derecho a la libertad personal, aunado al Pacto Internacional de Derechos Civiles y Políticos en su artículo 9, que de igual manera obliga al Estado colombiano a evitar las detenciones arbitrarias y a dar solución expedita a cualquier tipo de recurso o situación que conlleve la privación de la justicia de una persona.

A su turno, la Corte IDH ha sido enfática en establecer cuáles son los requisitos que debe observar la detención preventiva para ajustarse a los cánones de la $\mathrm{CADH}$. De ellos, es primordial que se use como una medida cautelar y no de carácter puniti$v o$, además de contar con un acervo probatorio fuerte y alejado de conjeturas o suposiciones sin fundamento. Dichas pruebas deben permitir una inferencia razonada de que la persona que participó en el ilícito será privada de la libertad en forma preventiva. Así, se aleja cualquier asomo de arbitrariedad que pueda poner en entredicho la medida. ${ }^{36}$

El profundo calado de naturaleza fundamental que ofrece este delicado tema ha sido tratado por la Corte Constitucional, que ha hecho énfasis en que la medida de detención preventiva en Colombia no disuena con lo que en su momento ha establecido la Corte IDH. Por el contrario, está en consonancia, ya que la aplicación de esta medida debe ser necesaria, adecuada, proporcional y razonable, es decir, no podrá caprichosamente ser aplicada sin atender a los criterios mencionados. No hacerlo resultaría en una infracción no solo a lo establecido por la Corte IDH, sino a lo dispuesto por el ordenamiento interno colombiano. ${ }^{37}$

Las dificultades que se presentan en la práctica frente al delicado equilibrio que se necesita mantener para decidir en qué casos debe aplicarse la detención preventiva han sido abordados, y queda claro que no en todos los casos deberá procederse con este mecanismo. Es más, debe ser excepcional y atender a lo que el legislador a su turno ha dispuesto en uso de su libertad de configuración. Con ello no desconocerán preceptos de derechos humanos, ya que si bien es cierto que la libertad y el principio

existe la falla en el servicio. Sentencia T-6.304.188 y T-6.390.556 (AC), Corte Constitucional de Colombia, 5 de julio de 2018.

35. Sentencia 47.854, Consejo de Estado de Colombia, 2018.

36. Sentencia D-9750, Corte Constitucional de Colombia, 2013.

37. Sentencia D-11214, Corte Constitucional de Colombia, 2016. 
de inocencia son cabeceras de garantismo en el ordenamiento jurídico, no menos cierto es que existen casos especiales en que la peligrosidad y la posible injerencia en temas de investigación de algunas personas justifican la medida.

Como se mencionó, el estrecho vínculo entre la detención preventiva y la privación injusta de la libertad es grande, ya que potencialmente la extensión ilegal de la primera puede dar lugar a incoar una acción tendiente a responsabilizar al Estado por dicha privación injusta de la libertad. La ley, en dicho sentido, se ha pronunciado dejando en claro que lo anterior es una posibilidad, ${ }^{38} \mathrm{y}$ así también lo ha afirmado el Consejo de Estado, que ha sobreentendido que el control difuso de convencionalidad debe ser estricto.

\section{El derecho a la vida, en sus dimensiones}

El derecho a la vida es un pilar fundamental en los ordenamientos jurídicos que hacen parte de la CADH (artículo 4.1), ${ }^{39}$ ya que su protección en las diversas formas y el mandato negativo frente a medidas que pudieran violarla son patentes. Sobre la pena de muerte, la Convención ha dejado claro que podrá utilizarse solo para los delitos más graves y en los países en que antes de la entrada en vigor de la CADH contaran con dicha medida; mientras que hay prohibición expresa de reinstaurar la pena capital en aquellos países en que no existiera a la hora de adherirse a al tratado.

Colombia no ha sido ajena al cuestionamiento por violaciones al derecho a la vida, ya que la conocida violencia que ha vivido ha desembocado en serios cuestionamientos al Estado por el actuar de sus agentes. El tema de las ejecuciones extrajudiciales ${ }^{40}$ ha permeado a la fuerza pública, por cuyas manos se han causado graves violaciones a los derechos humanos y al derecho internacional humanitario. Es evidente que en el uso del estricto control difuso de convencionalidad, el Estado debe actuar de forma asertiva investigando los hechos, sancionando a los responsables y reparando a aquellas personas que resultaron afectadas por el criminal actuar de quienes han perpetrado este tipo de actuaciones.

Tanto a nivel nacional como internacional, no solo se entiende la vida como un derecho en sí mismo, sino también en consideración a las diferentes aristas de influencia que tiene. La más evidente es el derecho a la vida digna, cuestión que contempla la Constitución Política de Colombia en su artículo 1 y la CADH en su artículo 5.2, según el cual una condición que no tiene dignidad o se encuentra bajo

38. Ley 270 D.O., 15 de marzo de 1996, artículos 65 y 70.

39. Convención Americana de Derechos Humanos, artículo 4.1: «Toda persona tiene derecho a que se respete su vida. Este derecho estará protegido por la ley y, en general, a partir del momento de la concepción. Nadie puede ser privado de la vida arbitrariamente».

40. Sentencia 38.757, Consejo de Estado de Colombia, 2016. 
situaciones que la merman o la hacen «indigna» será de igual forma atentatoria a este vital derecho.

La jurisprudencia de la Corte IDH ha sido firme frente al tema del derecho a la vida, al consignar que:

El derecho a la vida es un derecho humano fundamental, cuyo goce es un prerrequisito para el disfrute de todos los demás derechos humanos. De no ser respetado, todos los derechos carecen de sentido. En razón del carácter fundamental del derecho a la vida, no son admisibles enfoques restrictivos del mismo. En esencia, el derecho fundamental a la vida comprende, no solo el derecho de todo ser humano de no ser privado de la vida arbitrariamente, sino también el derecho a que no se le impida el acceso a las condiciones que le garanticen una existencia digna. Los Estados tienen la obligación de garantizar la creación de las condiciones que se requieran para que no se produzcan violaciones de ese derecho básico y, en particular, el deber de impedir que sus agentes atenten contra él. ${ }^{41}$

\section{La vida digna}

La dignidad de la vida ha sido un tema de copiosa jurisprudencia administrativa y constitucional, bajo el entendido de que la vida es el más fundamental de todos los derechos y que su privación o puesta en peligro a través de formas como la esclavitud, negación de servicios de salud o de alimentación, también afecta su libre desarrollo al vulnerar su órbita de dignidad. Es así que su amparo resulta ser un objetivo primordial de cualquier Estado bajo la fórmula de protección de «vida, honra y bienes». ${ }^{42}$

La salud es un tema central en la vida y la vida digna de las personas, cuya negación o deficiente prestación hace peligrar el bienestar y en ocasiones hasta la vida misma. Esto ha llevado a que la acción de tutela constitucional, ${ }^{43}$ aunado a la acción de reparación directa, sean mecanismos tanto de protección a derechos que aún no

41. Caso «Niños de la Calle» (Villagrán Morales y otros) con Guatemala, Corte Interamericana de Derechos Humanos, 1999.

42. El artículo 2 de la Constitución Política establece: «Las autoridades de la República están instituidas para proteger a todas las personas residentes en Colombia, en su vida, honra, bienes, creencias, y demás derechos y libertades, y para asegurar el cumplimiento de los deberes sociales del Estado y de los particulares».

43. Establece el artículo 86 de la Constitución: «Toda persona tendrá acción de tutela para reclamar ante los jueces, en todo momento y lugar, mediante un procedimiento preferente y sumario, por sí misma o por quien actúe a su nombre, la protección inmediata de sus derechos constitucionales fundamentales, cuando quiera que éstos resulten vulnerados o amenazados por la acción o la omisión de cualquier autoridad pública. La protección consistirá en una orden para que aquél respecto de quien se solicita la tutela, actúe o se abstenga de hacerlo». 
han generado perjuicios, en el caso de la primera, y como mecanismo de control que buscará resarcir perjuicios ya ocasionados, como en el caso de la segunda. ${ }^{44}$

Convencionalmente, Colombia ha adoptado el Pacto Internacional de Derechos Económicos, Sociales y Culturales (PIDESC) a través de la Ley 74 de 1968, en la que el Estado se obliga a procurar el más alto nivel de salud tanto físico como mental para todas las personas. Garantizar este derecho no solo es convencionalmente obligatorio, pues también ha sido garantizado a nivel legislativo, y su estrecho nexo con un derecho tan fundamental como la vida hace que ésta y la salud estén íntima e inescindiblemente ligadas (Ley 1.751, de 2015).

\section{Ejecuciones extrajudiciales, «falsos positivos»}

La responsabilidad del Estado colombiano no ha quedado indemne frente a los hechos que se han vivido, en que el derecho a la vida ha sido grotescamente desconocido a manos de agentes del Estado que, so pretexto de presentar resultados operacionales (bajas en combate), han ejecutado a personas haciéndolas pasar por combatientes, tema más conocido como los «falsos positivos», que en su momento han tratado tanto la jurisprudencia de la Corte Interamericana como la del Consejo de Estado de Colombia.

Es de aclarar que el tema de las ejecuciones extrajudiciales ha sido denominado como un acto mediante el cual una autoridad pública priva de la vida arbitraria y deliberadamente a una persona o a un grupo de personas, atendiendo de igual forma a un doble estándar: que debe imputarse este actuar a un servidor público, cuestión que se entiende bajo la lupa de la legalidad que deben observar las actuaciones de éstos, y que este actuar atente contra la vida de una persona o grupo de ellas (Ferrer Mac-Gregor, 2014: 41).

En países donde la violencia es endémica, el derecho a la vida se ha convertido en un derecho de difícil protección por parte del Estado, ya que - como es claro- el actuar de las autoridades no es suficiente, y existe una imposibilidad material de evitar en forma puntual cada caso. Aun así, hay obligación del Estado colombiano frente a casos que revisten gravedad mayor. Por ejemplo, en las ejecuciones extrajudiciales hay una obligación superior de investigar y llevar a la justicia a los perpetradores, y de indemnizar a las víctimas de forma integral, lo cual evidencia una curiosa e inapro-

44. Artículo 140: «Reparación directa. En los términos del artículo 90 de la Constitución Política, la persona interesada podrá demandar directamente la reparación del daño antijurídico producido por la acción u omisión de los agentes del Estado. De conformidad con el inciso anterior, el Estado responderá, entre otras, cuando la causa del daño sea un hecho, una omisión, una operación administrativa o la ocupación temporal o permanente de inmueble por causa de trabajos públicos o por cualquiera otra causa imputable a una entidad pública o a un particular que haya obrado siguiendo una expresa instrucción de la misma». 
piada distinción: no por el hecho de que una violación al derecho a la vida sea llevada a cabo por agentes del Estado merece más miramientos que cualquier otra violación al derecho a la vida. La obligación está en investigar de manera eficiente cualquier violación, aun cuando ésta potencialmente no comprometa la responsabilidad convencional del Estado.

La cifra - entre los varios miles- relacionada con ejecuciones extrajudiciales es una que se maneja frente a una situación que difícilmente es justificable, ya que en muchas ocasiones dichas «bajas» fueron el resultado del actuar de las fuerzas militares que buscaban evidenciar resultados en el conflicto que vive Colombia hace décadas, situación que se hizo evidente con el caso de los jóvenes de Soacha, que solo son la punta de un macabro iceberg (Rojas Bolaños y Benavides Silva, 2017); y en otros casos que han trascendido a instancias internacionales, como el de la masacre de Mapiripán, cuando, con la anuencia de miembros del Ejército, se produjo una masacre a manos de grupos paramilitares..$^{45}$

Es así que, mediante este procedimiento, se ha violado el derecho convencional a la vida que tan vehementemente ha defendido la Corte IDH y la Constitución Política de Colombia. A su vez, el Consejo de Estado ha hecho propia esta batalla mediante sendas jurisprudencias que han sancionado el antijurídico proceder de los agentes del Estado, quienes, valiéndose de dicha autoridad, han ocasionado graves violaciones a derechos humanos utilizando, como se explicó, a civiles que corrieron con la mala fortuna de pasar por retenes o transitar caminos que les llevaron a una muerte sin sentido y que fue justificada como el resultado de una guerra que requería cifras.

\section{La Corte Constitucional y el bloque de la constitucionalidad}

La Corte Constitucional, de acuerdo con el artículo 247 de la Carta, es la encargada de «la guarda de la integridad y supremacía de la Constitución», y en virtud de esta función será, de igual forma, una instancia decisoria en la exequibilidad de los tratados internacionales y de las leyes que los aprueban. Es así como el trabajo de la Corte frente a los tratados que se suscriben es determinante, ya que es aquí donde se origina el trabajo de la Corporación frente al tratamiento de lo que se denomina el bloque de la constitucionalidad.

Desde el año 1992, la Corte Constitucional ha desarrollado un precedente uniforme frente a lo que se llamaría posteriormente bloque de la constitucionalidad, ${ }^{46}$ término que hace alusión a aquellas normas que, aun no estando contenidas en la Carta, poseen la misma fuerza que ésta, como lo establece el artículo 93 de la Constitución, que al efecto reza: «Los tratados y convenios internacionales ratificados por el

45. Caso Masacre de Mapiripán con Colombia, Corte Interamericana de Derechos Humanos, 2005. 46. Véase sentencia C-574-1992 MP, Ciro Angarita Barón, Corte Constitucional de Colombia, 1992. 
Congreso, que reconocen los derechos humanos y que prohíben su limitación en los estados de excepción, prevalecen en el orden interno».

La prevalencia de los mencionados tratados internacionales que reconocen derechos humanos da luz a un concepto de bloque, como se mencionó, en que existen normas que si bien no están positivizadas dentro de la Constitución, poseen un poder comparable a ésta.

Es así que la Corte permite una distinción bipartita de lo que compone el bloque de la constitucionalidad como tal, en estricto sensu y lato sensu. El primero dispone que serán en el estricto sentido normas del bloque las contenidas en la Constitución y en los tratados que establece el artículo 93, es decir, los que traten derechos humanos y que no pueden ser limitados en estados de excepción. ${ }^{47}$ En el sentido lato, serán normas del bloque aquellas que, si bien no son del calado de las de la Constitución o de los tratados de derechos humanos, son superiores a las leyes ordinarias (estatutarias y orgánicas), que sirven como apoyo en el control de constitucionalidad. $4^{8}$

Es evidente la importancia que tiene la Corte Constitucional en el control de convencionalidad, al ser la doctrina interpretativa de ésta la que da prevalencia dentro del orden interno a un instrumento internacional como la CADH. La naturaleza de tratado de derechos humanos le da una importancia superlativa dentro del ordenamiento jurídico colombiano, de acuerdo con lo reglado en la Constitución Política, al punto de que su aplicación, dentro de los casos que se ventilen a nivel judicial tendrá, a la luz de control difuso de convencionalidad, la virtualidad de obligar a los jueces a respetar la convencionalidad y la interpretación de la Corte Constitucional.

Es menester dejar en claro que la dinámica naturaleza de los derechos humanos hace de las categorías establecidas en la jurisprudencia de la Corte Constitucional, como bloque de constitucionalidad, mutables y flexibles, ya que constantemente se sumarán nuevas dinámicas y entendidos acerca de estos fundamentales derechos incluidos en tratados internacionales que suscriba el Gobierno colombiano. Estos casos se evidencian en la inclusión de la mujer como sujeto de especial protección, los convenios de OIT (Arango Olaya, 2004) y aquellos que en el futuro se incluyan dentro de la categoría, como el derecho al agua, que si bien no tiene consagración internacional, sí ha sido considerado como elemento del bloque al ser tratado por la jurisprudencia de la Corporación. ${ }^{49}$

La jurisprudencia de la Corte IDH, como lo dispone la Corte Constitucional, guarda un lugar de alta importancia dentro de los ordenamientos jurídicos interamericanos. No obstante, su aplicación presenta una dificultad: esta es, que su «trasplante», por decirlo de alguna manera, es problemático, ya que se debe considerar

47. Sentencia C-191, Corte Constitucional de Colombia, 1998.

48. Sentencia C-774, Corte Constitucional de Colombia, 2001.

49. Sentencia T-641, Corte Constitucional de Colombia, 2015. 
el sistema al que se busca integrar y, si no se encuentra ese aspecto de relevancia y congruencia, podrá la Corte apartarse de la interpretación de la Corte IDH al hacer su análisis de convencionalidad.

La Corte Constitucional será entonces la guardiana de la interpretación y supremacía de la Constitución, además de uno de los pilares de la convencionalidad a nivel colombiano. Su jurisprudencia es unánime en cuanto a la importancia que reviste la CADH y a que su integración al ordenamiento jurídico debe ser total. No obstante, existe una posición de sano disenso en cuanto a la aplicación irrestricta de los efectos de la Convención, como se mencionó atrás, ya que en ocasiones podría chocar con barreras culturales y jurídicas propias de Colombia.

\section{Conclusiones}

El control de convencionalidad difuso es una institución jurídica de obligatoria utilización por parte de los jueces en Colombia y sus homólogos pertenecientes a la órbita interamericana. Su continuo uso ha creado una disciplina de precedente que no solo se agota con la utilización del decálogo de derechos enunciados en la Convención, sino también con los diferentes instrumentos internacionales que versan sobre derechos humanos que en el ordenamiento jurídico colombiano prevalecen. También en cierta medida de la jurisprudencia, que, como se acotó, tiene un rango de obligatoriedad total para los Estados que la Corte ha juzgado y — es dable afirmar- es persuasivo para los demás.

El Consejo de Estado de Colombia, como máximo ente de lo contencioso administrativo, tiene una obligación superlativa frente al control de convencionalidad, ya que su estado de órgano de cierre le impone la responsabilidad de ser un mecanismo de control que evitará a futuro las condenas al Estado en sede interamericana, ya que si se cumple no solo con la indemnización de corte económico, sino también con aquellas medidas de satisfacción que de forma integral reparan los daños vividos, la función de cumplir con el acceso a la justicia estará garantizada y se evitará un control posterior, que muy probablemente le será desfavorable el Estado.

La obligación de aplicar el control difuso de convencionalidad es aplicable a todos los jueces, tanto en Colombia como en los demás países que se han acogido a la justicia interamericana, ya que están llamados a aplicar sin distingos no solo lo que la Constitución y la ley de su país les obliga, sino también a observar lo establecido en la Convención Americana de Derechos Humanos, tratados en los que el Estado es parte, y además las interpretaciones que ha hecho la Corte IDH acerca del articulado de la Convención. A esto debe agregarse que cada Estado proporcionará a sus jueces un papel más o menos fuerte en el control de convencionalidad, permitiendo que se hagan controles in situ o con formas menos participativas, en los que el expediente deberá remitirse a los superiores con la argumentación del caso. 
Es dable concluir que la responsabilidad del Estado está inescindiblemente ligada al control de convencionalidad, ya que si las normas internas no proveen un mecanismo idóneo o argumentación suficiente frente a una violación de derechos humanos, bastará que se invoque la Convención Americana como fundamento para condenar al Estado, ya que esta norma supranacional tiene vigencia dentro del orden interno colombiano, inclusive por encima de la ley y la Constitución, cuestión que ya ha vivido la jurisprudencia del Consejo de Estado y de la que se ha favorecido el corpus iuris interamericano.

Colombia ha sido un Estado en que el control de convencionalidad difuso ha tenido un ambiente propicio para su desarrollo, ya que como se evidenció en este trabajo, la jurisprudencia ha sido nutrida y apoyada por la misma Constitución Política que permite, sin obstáculos más que el argumentativo, inaplicar una norma utilizando el mecanismo de la excepción de inconstitucionalidad, cuestión que se puede hacer extensiva a la convencionalidad, lo que permite de esta manera mantener el ordenamiento jurídico a tono con lo dispuesto por la CIDH.

Si bien existe una gran exigencia frente a la interpretación conforme que debe hacerse en los diferentes ordenamientos jurídicos de lo establecido en la CADH, también es posible que en un momento concreto pueda existir un disenso argumentado y sustentado de por qué la aplicación del precedente de la Corte IDH resulta inconveniente. Lo anterior respeta la independencia judicial, un derecho constitucionalmente protegido por la Carta colombiana.

\section{Referencias}

Arango Olaya, Mónica (2004). «El bloque de constitucionalidad en la jurisprudencia de la Corte Constitucional colombiana». Precedente, 4: 79-102. DOI: 10.18046/ prec.vo.1406.

Brewer-Carías, Allan R. y Jaime O. Santofimio Gamboa (2013). Control de convencionalidad y responsabilidad del Estado. Bogotá: Editorial Universidad Externado de Colombia.

CAlderón GAmboa, Jorge (2013). «La reparación integral en la Corte Interamericana de Derechos Humanos: Estándares aplicables al nuevo paradigma mexicano». En Derechos humanos en la Constitución: Comentarios de jurisprudencia constitucional e interamericana (pp. 147-219). Ciudad de México: Suprema Corte de la Nación. Disponible en https://bit.ly/324x5mb.

FERrer MAC-Gregor, Eduardo (2011). «Interpretación conforme y control difuso de convencionalidad: El nuevo paradigma para el juez mexicano». Estudios Constitucionales, 9 (2): 531-622. Disponible en https://bit.ly/2W48J83.

-. (2014). «Las siete principales líneas jurisprudenciales de la Corte Interamericana 
de Derechos Humanos aplicable a la justicia penal». Revista IIDH, 59: 29-118. Disponible en https://bit.ly/2DyMMbb.

Gil Botero, Enrique (2019). Control de convencionalidad en Colombia: Una experiencia de diálogo judicial. Valencia: Tirant lo Blanch.

Henao, Juan Carlos (2015). La responsabilidad extracontractual del Estado: ¿Qué? ¿Por qué? ¿Hasta dónde? XVI Jornadas Internacionales de Derecho Administrativo. Bogotá: Externado de Colombia.

Hitters, Juan Carlos (2008). «¿Son vinculantes los pronunciamientos de la Comisión y de la Corte Interamericana de Derechos Humanos? (Control de constitucionalidad y convencionalidad)». Revista Iberoamericana de Derecho Procesal Constitucional, 10: 131-156. Disponible en https://bit.ly/2W9jLsP.

LeDESMA, Héctor Faúndez (2007). «El agotamiento de los recursos internos en el sistema interamericano de protección de los derechos humanos». Centro de Estudios de Derechos Humanos, Universidad Central de Venezuela. Disponible en https://bit.ly/2W814Z5.

Rojas Bolaños, Ornar Eduardo y Fabián Leonardo Benavides Silva (2017). Ejecuciones extrajudiciales en Colombia, 2002-2010: Obediencia ciega en campos de batalla ficticios. Bogotá: USTA.

\section{Sobre el autor}

William Eugene Ulrich Astaiza es abogado de la Universidad Cooperativa de Colombia. Especialista en derecho y magíster en Derecho Administrativo de la Universidad del Cauca, Colombia. Doctorando en Estudios Avanzados en Derechos Humanos en la Universidad Carlos Tercero, España. Profesor de tiempo completo de la Universidad Cooperativa de Colombia y asesor de la Maestría en Derecho Administrativo de la Universidad del Cauca. Su correo electrónico es william.ulricha@ campusucc.edu.co. (D) https://orcid.org/oooo-0003-4652-4486. 
El Anuario de Derechos Humanos es una publicación semestral de referencia y consulta en materia de derechos humanos y campos afines. Busca ser un espacio de discusión de los temas centrales en el ámbito nacional e internacional sobre derechos humanos. Es publicado desde 2005 por el Centro de Derechos Humanos de la Facultad de Derecho de la Universidad de Chile.

\author{
EDITORA \\ Claudia Iriarte Rivas \\ ciriarter@derecho.uchile.cl \\ SITIO WEB \\ anuariocdh.uchile.cl \\ CORREO ELECTRÓNICO \\ anuario-cdh@derecho.uchile.cl \\ LICENCIA DE ESTE ARTÍCULO \\ Creative Commons Atribución Compartir Igual 4.o Internacional
}

\author{
\% \\ La edición de textos, el diseño editorial \\ y la conversión a formatos electrónicos de este artículo \\ estuvieron a cargo de Tipográfica \\ (www.tipografica.io)
}

